\title{
PROFIL KONDISI FISIK ATLET PANAHAN GRESIK
}

\author{
Teguh Dwi Putranto ${ }^{1 *}$, Fifit Yeti Wulandari ${ }^{2}$, Aghus Sifaq $^{3}$ \\ ${ }^{123}$ Jurusan Pendidikan Kepelatihan Olahraga, Universitas Negeri Surabaya, Indonesia \\ *fifityeti@unesa.ac.id
}

(Received: December 2018 / Revised: February 2018 / Accepted: March 2018)

\begin{abstract}
ABSTRAK: Perkembangan prestasi panahan Gresik mulai menunjukkan prestasi yang cukup diperhitungkan. Hal tersebut tidak lepas dari pembinaan dalam hal teknik saja namun juga fisik. Kondisi fisik disini merupakan faktor penting dalam menyeimbangkan teknik, mental dan taktik dalam mencapai sebuah prestasi. Dengan memiliki data kondisi fisik atlet maka akan dengan mudah bagi pelatih untuk memberikan porsi latihan kepada atletnya dan juga sebagai evaluasi kemajuan atlet Panahan Gresik dari waktu ke waktu. Berdasarkan hasil penelitian profil tingkat kondisi fisik atlet putra dan putri panahan Gresik usia 8 15 tahun yang sudah dilakukan maka telah diperoleh kesimpulan bahwa rata-rata (Mean) atlet putra untuk kekuatan otot bahu (menarik) sebesar 15,75 kg dengan kategori cukup, kekuatan otot bahu (mendorong) sebesar 11,5 kg dengan kategori cukup, kelentukan sebesar 28,87 cm dengan kategori cukup, daya tahan (Bleep) sebesar 23,5 dengan kategori kurang. Untuk atlet putri rata - rata (Mean) kekuatan otot bahu (menarik) sebesar 11,5 kg dengan kategori cukup, kekuatan otot bahu (mendorong) sebesar 10,25 $\mathrm{kg}$ dengan kategori baik, kelentukan pada atlet putri sebesar $32,65 \mathrm{~cm}$ dengan kategori cukup, daya tahan (Bleep) sebesar 20,8 dengan kategori cukup.

KATA KUNCI: Profil, Kondisi fisik, Panahan Gresik.
\end{abstract}

ABSTRACTS: The development of Gresik archery begin to show the achievement which is quite factored. It is not out of the coaching technique, but also physically. The physical condition here is an important factor in balancing technique, mental and tactics to reach an achievement. By having the physical condition data of athletes it will be easy for the coach to give a portion of the exercise to athletes as well as the evaluation progress evaluation of Gresik Archery athletes from time to time. Based on the results of the research profile of the physical condition level of male and female athletes archery Gresik aged 8-15 years that have done so we can conclude that the average (mean) male athlete for shoulder muscle strength (pull) is $15.75 \mathrm{~kg}$ with enough categories, shoulder muscle strength (push) is $11.5 \mathrm{~kg}$ with enough categories, flexibility is $28.87 \mathrm{~cm}$ with enough categori, endurance (Bleep) is 23.5 to less category. For female athletes average (Mean) shoulder muscle strength (pull) is $11.5 \mathrm{~kg}$ with enough categories, shoulder muscle strength (push) is 10.25 $\mathrm{kg}$ with good category, flexibility in female athletes is $32.65 \mathrm{~cm}$ by category enough, endurance (Bleep) is 20.8 with enough categories.

KEYWORD:

Profile, physical condition, Gresik Archery.

\section{PENDAHULUAN (Calibri 11 Bold)}

Prestasi yang baik tentunya tidak terlepas dari kondisi fisik yang baik pula. Kondisi fisik yang baik dalam panahan lebih dominan ke arah kekuatan, daya tahan dan kelentukan. Kekuatan dalam panahan terjadi pada saat transfer dan loading yang diawali dari posisi set up (mengangkat busur dan membidik) dan diteruskan proses menarik sampai nantinya ke posisi anchor (menahan).
Kelentukan dalam panahan diperlukan dari posisi anchor (menahan) menuju release (melepas anak panah) terdapat proses extending (menunggu anak panah melewati clicker). Saat anak panah akan melewati clicker posisi badan sampai jari-jari harus berada dalam posisi yang tidak tegang atau kaku. Karena kelentukan yang baik akan mempengaruhi anak panah akan lepas dengan baik. 
Daya tahan dibutuhkan dalam panahan karena dalam memanah terjadi proses dari set up (mengangkat busur dan mengatur bidikan) sampai release (melepaskan anak panah) selama berkalikali dimana selain itu juga menahan beban yang berat. Oleh karena itu dibutuhkan daya tahan yang baik agar atlet mampu mempertahankan dirinya saat perlombaan berlangsung. Ketiga komponen fisik inilah yang menjadi indikator kondisi fisik atlet.

Kategori kondisi fisik yang dihasilkan nantinya akan didapat dari hasil pengukuran dari serangkaian tes yang sesuai dengan komponen yang akan diujikan. Setelah tes dan pengukuran selesai dilakukan maka akan keluar hasil dari tes dan pengukuran masing-masing atlet. Hasil tersebut nantinya akan dicocokkan dengan norma-norma yang sudah ada. Setelah itu akan diketahui hasil akhir dari penelitian yang ingin kita ketahui.

Dengan memiliki data kondisi fisik atlet maka akan dengan mudah bagi pelatih untuk memberikan porsi latihan kepada atletnya karena dengan memberikan latihan yang sesuai dengan kebutuhan atlet maka akan dengan mudah untuk menaikkan skor atlet Panahan Gresik saat memanah. Selain itu juga bisa sebagai evaluasi kemajuan atlet Panahan Gresik dari waktu ke waktu karena dengan adanya data kondisi fisik maka mudah untuk mengetahui tingkat keberhasilan program latihan yang telah dilakukan sebelumnya.

Berdasarkan latar belakang di atas penulis berkesimpulan bahwa penelitian ini penting untuk dilakukan agar permasalahan tersebut dapat diselesaikan sehingga ke depan akan diketahui status kondisi fisik atlet panahan gresik dari waktu ke waktu, dimana data tersebut dapat digunakan sebagai bahan untuk evaluasi program latihan yang telah dilaksanakan sebelumnya.

\section{METODE PENELITIAN}

Jenis penelitian ini adalah penelitian kuantitatif dengan pendekatan deskriptif yang merupakan metode penelitian yang berusaha mengambarkan objek atau subjek yang diteliti sesuai dengan apa adanya dengan tujuan menggambarkan secara sistematis fakta dan karateristik objek yang diteliti secara tepat (Sukardi, 2003:163).

\section{a. Subyek Penelitian}

Subyek penelitian ini adalah atlet panahan putra dan putri Gresik yang berjumlah delapan orang yaitu empat putra dan empat putri. Dengan usia berkisar 8-15 tahun dengan menggunakan serangkaian tes kondisi fisik.

\section{b. Teknik Pengumpulan Data}

Dalam penelitian ini, untuk mengumpulkan data yang valid dan akurat, harus menjalankan tes sesuai dengan norma dan prosedur tes, karena dalam penelitian ini terdapat 4 (empat) tes yang akan dilakukan yaitu :

- Tes kekuatan menarik otot bahu menggunakan tes Expanding Dynamometer

- Tes kekuatan mendorong otot bahu menggunakan tes Expanding Dynamometer

- Tes kelentukan menggunakan tes Sit and Reach

- Tes daya tahan menggunakan mengunakan tes Bleep.

c. Teknik Analisis Data

- Mean untuk mengetahui rata-rata $\overline{\mathrm{X}}=\frac{\sum \mathrm{X}}{n}$ (Martini, 2007: 11)

Keterangan :

$$
\begin{array}{ll}
\overline{\mathrm{X}} & =\text { Rata }- \text { rata sampel } \\
\Sigma \mathrm{X} & =\text { Skor dalam sampel } \\
\mathrm{n} & =\text { Banyak skor }
\end{array}
$$

- Persentase

$$
P=\frac{\mathrm{n}}{\mathrm{N}} \times 100 \%
$$

(Maksum, 2007:8)

Keterangan : 
$\mathrm{P}=$ Persentase

$\mathrm{n}$ = Jumlah nilai realita yang diperoleh

$\mathrm{N}=$ Jumlah sampel

\section{HASIL}

Tabel 1. Data Hasil Tes Atlet Putra Panahan Gresik

\begin{tabular}{|c|c|c|c|c|c|c|}
\hline $\begin{array}{l}\mathbf{N} \\
\mathbf{0}\end{array}$ & $\begin{array}{l}\mathbf{N} \\
\mathbf{A} \\
\mathrm{m} \\
\mathrm{a}\end{array}$ & $\begin{array}{l}U \\
S \\
\text { I } \\
a\end{array}$ & $\begin{array}{l}\text { Kekuat } \\
\text { an Otot } \\
\text { Bahu } \\
\text { (menari } \\
\text { k) }\end{array}$ & $\begin{array}{l}\text { Kekuatan } \\
\text { Otot Bahu } \\
\text { (mendoro } \\
\text { ng) }\end{array}$ & $\begin{array}{l}\text { Kelentuk } \\
\text { an }\end{array}$ & $\begin{array}{l}\text { Daya } \\
\text { Taha } \\
\mathrm{n} \\
\text { (Blee } \\
\text { p) }\end{array}$ \\
\hline 1. & $\mathrm{RE}$ & 15 & $21 \mathrm{Kg}$ & $2 \mathrm{Kg}$ & $34,5 \mathrm{Cm}$ & 22,8 \\
\hline 2. & $\mathrm{IK}$ & 12 & $8 \mathrm{Kg}$ & $7 \mathrm{Kg}$ & $22 \mathrm{Cm}$ & 22,8 \\
\hline 3. & IF & 14 & $19 \mathrm{Kg}$ & $22 \mathrm{Kg}$ & $42,5 \mathrm{Cm}$ & 27,2 \\
\hline 4. & YA & 13 & $15 \mathrm{Kg}$ & $2 \mathrm{Kg}$ & $12,5 \mathrm{Cm}$ & 21,2 \\
\hline & an & & $15,75 \mathrm{Kg}$ & $11,5 \mathrm{Kg}$ & $28,8 \mathrm{Cm}$ & 23,5 \\
\hline
\end{tabular}

Pada atlet putra panahan Gresik usia $8-15$ tahun nilai tertinggi dari tes kekuatan otot bahu (menarik) yang diperoleh adalah mencapai $21 \mathrm{~kg}$ dan nilai terendah mencapai $8 \mathrm{~kg}$. Dengan rata rata (Mean) sebanyak 15,75. Hasil penghitungan persentase dari tes kekuatan otot bahu (menarik) atlet putra panahan Gresik adalah $50 \%$ dengan jumlah atlet sebanyak 2 orang masuk dalam kategori baik sekali, $25 \%$ dengan jumlah atlet 1 orang masuk dalam kategori cukup, dan $25 \%$ dengan jumlah atlet 1 orang masuk dalam kategori kurang sekali.

Pada atlet putra panahan Gresik usia $8-15$ tahun nilai tertinggi dari tes kekuatan otot bahu (mendorong) yang diperoleh adalah mencapai 22 $\mathrm{kg}$ dan nilai terendah mencapai $2 \mathrm{~kg}$. Dengan rata - rata (Mean) sebanyak 11,5. Hasil penghitungan persentase dari tes kekuatan otot bahu (mendorong) atlet putra panahan Gresik adalah $25 \%$ dengan jumlah atlet sebanyak 1 orang masuk dalam kategori baik sekali, $25 \%$ dengan jumlah atlet 2 orang masuk dalam kategori kurang, dan $50 \%$ dengan jumlah atlet 2 orang masuk dalam kategori kurang sekali.

Pada atlet putra panahan Gresik usia 8 - 15 tahun nilai tertinggi dari tes kelentukan yang diperoleh adalah mencapai $42,5 \mathrm{~cm}$ dan nilai terendah mencapai $12,5 \mathrm{~cm}$. Dengan rata - rata
(Mean) sebanyak $28,87 \mathrm{~cm}$. Hasil penghitungan persentase dari tes kelentukan atlet putra panahan Gresik adalah $25 \%$ dengan jumlah atlet sebanyak 1 orang masuk dalam kategori baik sekali, $25 \%$ dengan jumlah atlet sebanyak 1 orang masuk dalam kategori baik, $25 \%$ dengan jumlah atlet 1 orang masuk dalam kategori kurang, dan $25 \%$ dengan jumlah atlet 1 orang masuk dalam kategori kurang sekali.

Pada atlet putra panahan Gresik usia $8-15$ tahun nilai tertinggi dari tes daya tahan bleep yang diperoleh adalah mencapai 27,2 dan nilai terendah mencapai 21,2. Dengan rata - rata (Mean) sebanyak 23,5. Hasil penghitungan persentase dari tes daya tahan bleep atlet putra panahan Gresik adalah $25 \%$ dengan jumlah atlet sebanyak 1 orang masuk dalam kategori baik sekali, $50 \%$ dengan jumlah atlet 2 orang masuk dalam kategori baik, dan $25 \%$ dengan jumlah atlet 1 orang masuk dalam kategori kurang sekali.

Tabel 2. Data Hasil Tes Atlet Putr1 Panahan Gresik

\begin{tabular}{|c|c|c|c|c|c|c|}
\hline $\begin{array}{l}\mathbf{N} \\
\mathbf{0}\end{array}$ & $\begin{array}{l}\mathbf{N} \\
\mathbf{A} \\
\mathbf{m} \\
\mathrm{a}\end{array}$ & $\begin{array}{l}\text { U } \\
\text { S } \\
\text { I } \\
\text { a }\end{array}$ & $\begin{array}{l}\text { Kekuat } \\
\text { an Otot } \\
\text { Bahu } \\
\text { (menari } \\
\text { k) }\end{array}$ & $\begin{array}{l}\text { Kekuatan } \\
\text { Otot Bahu } \\
\text { (mendoro } \\
\text { ng) }\end{array}$ & $\begin{array}{l}\text { Kelentuk } \\
\text { an }\end{array}$ & $\begin{array}{l}\text { Daya } \\
\text { Taha } \\
\mathrm{n} \\
\text { (Blee } \\
\text { p) }\end{array}$ \\
\hline & RO & 13 & $15 \mathrm{Kg}$ & $11 \mathrm{Kg}$ & $36,5 \mathrm{Cm}$ & 21,2 \\
\hline & EL & 8 & $8 \mathrm{Kg}$ & $9 \mathrm{Kg}$ & $27,5 \mathrm{Cm}$ & 20,8 \\
\hline 3. & IN & 8 & $11 \mathrm{Kg}$ & $12 \mathrm{Kg}$ & $28,5 \mathrm{Cm}$ & 20,8 \\
\hline 4. & SU & 15 & $12 \mathrm{Kg}$ & $9 \mathrm{Kg}$ & $38 \mathrm{~cm}$ & 20,4 \\
\hline & ean & & $\mathrm{L} 1,5 \mathrm{Kg}$ & $10,25 \mathrm{Kg}$ & $32,6 \mathrm{Cm}$ & 20,8 \\
\hline
\end{tabular}

Pada atlet putri panahan Gresik usia $8-15$ tahun nilai tertinggi dari tes kekuatan otot bahu (menarik) yang diperoleh adalah mencapai $15 \mathrm{~kg}$ dan nilai terendah mencapai $8 \mathrm{~kg}$. Dengan rata rata (Mean) sebanyak 11,5. Hasil penghitungan persentase dari tes kekuatan otot bahu (menarik) atlet putri panahan Gresik adalah 50 \% dengan jumlah atlet sebanyak 2 orang masuk dalam kategori baik sekali, $25 \%$ dengan jumlah atlet 1 orang masuk dalam kategori cukup, dan $25 \%$ dengan jumlah atlet 1 orang masuk dalam kategori kurang sekali. 
Pada atlet putri panahan Gresik usia 8 - 15 tahun nilai tertinggi dari tes kekuatan otot bahu (mendorong) yang diperoleh adalah mencapai 12 $\mathrm{kg}$ dan nilai terendah mencapai $9 \mathrm{~kg}$. Dengan ratarata (Mean) sebanyak 10,25 kg. Hasil penghitungan persentase dari tes kekuatan otot bahu (mendorong) atlet putri panahan Gresik adalah $50 \%$ dengan jumlah atlet sebanyak 2 orang masuk dalam kategori baik sekali, dan $50 \%$ dengan jumlah atlet 2 orang masuk dalam kategori kurang sekali.

Pada atlet putri panahan Gresik usia $8-15$ tahun nilai tertinggi dari tes kelentukan yang diperoleh adalah mencapai $38 \mathrm{~cm}$ dan nilai terendah mencapai $27,5 \mathrm{~cm}$. Dengan rata - rata (Mean) sebanyak $32,65 \mathrm{~cm}$. Hasil penghitungan persentase dari tes kelentukan atlet putri panahan Gresik adalah $50 \%$ dengan jumlah atlet sebanyak 2 orang masuk dalam kategori baik sekali, dan 50 $\%$ dengan jumlah atlet 2 orang masuk dalam kategori kurang sekali.

Pada atlet putri panahan Gresik usia 8 - 15 tahun nilai tertinggi dari tes daya tahan bleep yang diperoleh adalah mencapai 21,2 dan nilai terendah mencapai 20,4. Dengan rata - rata (Mean) sebanyak 20,8. Hasil penghitungan persentase dari tes daya tahan bleep atlet putri panahan Gresik adalah $25 \%$ dengan jumlah atlet sebanyak 1 orang masuk dalam kategori baik sekali, $50 \%$ dengan jumlah atlet 2 orang masuk dalam kategori cukup, dan $25 \%$ dengan jumlah atlet 1 orang masuk dalam kategori kurang sekali.

\section{PEMBAHASAN}

Hasil dari tes yang sudah dilakukan pada atlet putra panahan Gresik menunjukkan bahwa kekuatan otot bahu (menarik) mayoritas masuk dalam kategori baik, kekuatan otot bahu (mendorong) mayoritas masuk dalam kategori kurang sekali, kelentukan mayoritas masuk dalam kategori rata antara baik sekali, baik, kurang, kurang sekali. Pada daya tahan mayoritas masuk dalam kategori kurang.

Hasil dari tes yang sudah dilakukan pada atlet putri panahan Gresik menunjukkan bahwa kekuatan otot bahu (menarik) mayoritas masuk dalam kategori baik, kekuatan otot bahu (mendorong) mayoritas masuk dalam kategori baik sekali dan kurang sekali, kelentukan mayoritas masuk dalam kategori baik sekali dan kurang sekali. Pada daya tahan Bleep mayoritas masuk dalam kategori kurang.

Seorang atlet panahan harus mempunyai kondisi fisik yang prima untuk dapat mencapai suatu prestasi yang diinginkan. Seperti pada saat atlet melakukan latihan dalam durasi yang lama, atlet harus mempunyai daya tahan yang bagus agar dapat mempertahankan hasil tembakan secara maksimal dan dengan jangka waktu yang lama. Sebaliknya apabila atlet tidak mempunyai daya tahan yang bagus maka, kualitas hasil tembakan akan menurun. Untuk meningkatkan daya tahan, bisa dilakukan dengan latihan Cross Country (Lee, 2005: 148).

Di dalam panahan kekuatan otot bahu juga sangat berperan penting untuk dapat mengangkat, menarik, menahan, sampai melepas anak panah. Oleh sebab itu perlu dilakukan suatu latihan yang terprogram untuk melatih kekuatan otot tersebut. Misalnya pada latihan weight training. Sajoto mengungkapkan, Program latihan peningkatan kekuatan otot yang paling efektif adalah program latihan dengan memakai beban atau weight training. (Sajoto, 1988: 114). Apabila semua komponen kondisi fisik sudah terpenuhi maka semakin mudah atlet mencapai prestasi tertinggi.

\section{SIMPULAN DAN REKOMENDASI}

Berdasarkan hasil penelitian profil tingkat kondisi fisik atlet panahan Gresik yang sudah dilakukan maka telah diperoleh kesimpulan Kekuatan otot bahu (menarik) pada atlet putra 
panahan Gresik masuk ke dalam kategori cukup. Kekuatan otot bahu (mendorong) pada atlet putra panahan Gresik masuk ke dalam kategori cukup. Kelentukan pada atlet putra panahan Gresik masuk ke dalam kategori cukup. Daya tahan (Bleep) pada atlet putra panahan Gresik masuk ke dalam kategori kurang. Kekuatan otot bahu (menarik) pada atlet putri panahan Gresik masuk ke dalam kategori cukup. Kekuatan otot bahu (mendorong) pada atlet putri panahan Gresik masuk ke dalam kategori baik. Kelentukan pada atlet putri panahan Gresik masuk ke dalam kategori cukup. Daya tahan (Bleep) pada atlet putri panahan Gresik masuk ke dalam kategori cukup.

Menurut hasil penelitian yang telah diperoleh, peneliti memberikan saran sebagai berikut: Untuk pelatih panahan Gresik perlu memberikan latihan umum guna meningkatkan kekuatan otot bahu dan daya tahan atlet, karena mayoritas hasil tes yang dilakukan masuk dalam kategori kurang. Untuk Perpani Gresik diharapkan agar lebih memperhatikan kondisi atlet panahan Gresik dengan cara melakukan tes secara berkala agar program latihan yang terukur dan terarah yang telah dibuat bisa dijadikan acuan ke depannya. Untuk atlet panahan Gresik diharapkan agar meningkatkan latihan baik itu teknik atau fisik. Karena dengan latihan yang berkelanjutan akan mendapatkan hasil yang baik

\section{UCAPAN TERIMAKASIH}

Terimakasih penulis ucapkan kepada dosen pembimbing yang telah membimbing penulis sehingga penelitian ini dapat berjalan dengan apa yang telah direncanakan.

\section{REFERENSI}

A.Barret, Jean. 1990. Olahraga Panahan Pedoman, Teknik, Analisa. Semarang:Effhar \& Dara Prize.

Badudu, Z. Kamus Umum Bahasa Indonesia. Jakarta: Pustaka Sinar Harapan.
Dr Noerbai, M.Pd. 2001. Memahami Falsafah Olahraga Panahan. Surabaya: Unesa University Press.

Lee, Kisik., and Robert de Bondt. 2005. Total Archery. Republik of Korea: SAMICK SPORT CO.,LTD.

Maksum, Ali. 2008. Metodelogi Penelitian dalam Olahraga. FIK UNESA.

Martini, 2007. Prosedur dan Prinsip-prinsip Statistika. Surabaya: Unesa University Press.

McKinney. Rick. 1996. The Simple Art Of Winning. Japan: Leo Planning, Inc.

Menegpora. 2005. Panduan Penetapan Parameter Tes Pada Pusat Pendidikan Dan Pusat Pelatihan Pelajar Dan Sekolah Khusus Olahragawan. Jakarta: Deputi peningkatan prestasi dan iptek olahraga

Nurhasan. 1986. Macam-Macam Jenis Tes Keolahragaan dan Pengukuran Unsur-Unsur Gerak Dalam Olahraga Tes Dan Pengukuran.

Nurhasan. 2003. Tes Dan Pengukuran. Bandung: Universitas Pendidikan Indonesia.

Oky R, Kolektus. Hubungan Kecemasan Dengan Hasil Tembakan Olahraga Panahan Jarak $10 \mathrm{~m}$ Pada Ekstrakulikuler Panahan SMAN 1 Srengat Blitar. Pendidikan Olahraga. UNESA

Penyusun Unesa, 2006. Panduan Penulisan dan Penilaian Skripsi. Surabaya:Universitas Negeri Surabaya.

Sajoto, Mochamad. 1988. Pembinaan Kondisi Fisik Dalam Olahraga. Jakarta: Proyek Pengembangan Lembaga Pendidikan Tenaga Kependidikan.

Sajoto. 1995. Peningkatan dan Pembinaan kekuatan Kondisi Fisik Dalam Olahraga. Jakarta : Depdikbud Dirjen PTPLPTP.

Sriundy Mahardika, I Made. 2010. Pengantar Evaluasi Pengajaran. Surabaya: Unesa University Press.

Sukardiyanto, 2005. Pengantar Teori dan Metodologi Melatih Fisik. Yogyakarta: Universitas Negeri Yogyakarta. 